\section{Ultrafiltration Membrane for Degumming of Crude Palm Oil-Isopropanol Mixture}

\author{
N. Aryanti, ${ }^{a, b, *}$ D. Hesti Wardhani, ${ }^{a}$ and A. Nafiunisa ${ }^{a}$ \\ ${ }^{a}$ Department of Chemical Engineering, Diponegoro University \\ ${ }^{\mathrm{b}}$ Membrane Research Centre (MeR-C), Diponegoro University
}

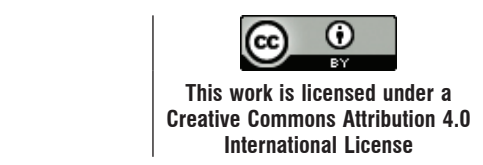

doi: 10.15255/CABEQ.2017.1244

Original scientific paper

Received: October 24, 2017

Accepted: August 1, 2018

Ultrafiltration (UF) is a membrane technology that has been applied for crude palm oil (CPO) degumming. It is considered as an alternative for the conventional CPO degumming technology because of its lower energy consumption, no need for the addition of chemicals, and almost no loss of natural oil. In this research, we separated a CPO-isopropanol mixture via laboratory-made flat-sheet polyethersulfone (PES) UF. Flux profiles confirmed that the increase in the $\mathrm{CPO}$ concentration resulted in lower fluxes. However, increasing the temperature from $30^{\circ} \mathrm{C}$ to $45^{\circ} \mathrm{C}$ initially raised the flux, but it was further decreased when the feed temperature was raised from $40{ }^{\circ} \mathrm{C}$ to $45^{\circ} \mathrm{C}$. Using UF of the CPO-isopropanol mixture at crude oil concentrations of $30 \%$ and $40 \%$, we were able to reject more than $99 \%$ phospholipids and nearly $93 \%$ phospholipids, respectively. However, the separation of free fatty acids using this process was ineffective due to the small size of free fatty acids. Through the evaluation of the blocking mechanism in the Hermia model, it was proposed that the standard and intermediate blocking were the dominant mechanisms of filtration of CPO at a concentration of 30 and $40 \%$, and 50 and $60 \%$, respectively.

Keywords:

crude palm oil, ultrafiltration, degumming

\section{Introduction}

Crude vegetable oil is a raw material used in the production of edible vegetable oil. Some examples of crude vegetable oils include crude palm oil (CPO), crude soybean oil, crude corn oil, crude coconut oil, crude sunflower oil, and crude castor oil ${ }^{1}$. Indonesia is one of the largest producers of $\mathrm{CPO}$, followed by Malaysia, Thailand, Colombia, and Nigeria. Compared to other oilseed crops, palm oil produces more oil products ${ }^{2}$. Compared to other vegetable oils, it is preferable in many applications as it is substantially cost-effective ${ }^{3}$. CPO is widely used in various food and industrial products' manufacturing processes, such as ice cream, frying oils, shortening, cosmetics, toothpastes, and biodiesel ${ }^{4}$. $\mathrm{CPO}$ is extracted from the ripe mesocarp of the fruit of oil palm trees (Elaeis guineensis) through various methods, such as mechanical pressing followed by solid-liquid extraction ${ }^{2}$.

The crude oil extracted from palm oil fruits is also rich in palmitic acid, $\beta$-carotene, and vitamin E, along with some undesirable compounds, such as

"Corresponding author: email: nita.aryanti@che.undip.ac.id phospholipids, free fatty acids (FFA), pigments, and proteins $^{5-6}$. CPO is composed of a vast number of triglycerides (TAGs) and $6 \%$ diglycerides (DAGs) that naturally consist of $\mathrm{FFA}^{7}$. Industrial regulations expect that high-quality oil must contain more than $95 \%$ neutral TAGs and $0.5 \%$ or less FFA; for some reason, the limit also decreases to less than $0.1 \%{ }^{2,8}$.

Complex refining processes including degumming, neutralization, bleaching, and deodorization are performed to meet the desired requirement. The first step in the refining process is degumming, the function of which is to remove phospholipids and mucilaginous gums. Conventional degumming methods using water and acids possess numerous drawbacks due to the high energy consumption, oil loss, loss of nutrients, and requirement for large water quantities ${ }^{9-10}$. The membrane-based filtration process is a promising method for refining palm oil. Membrane filtration provides low energy consumption, without the addition of chemicals and with almost no loss of natural oil ${ }^{11-12}$. Previous studies on $\mathrm{CPO}$ refining using membrane filtration have been evaluated ${ }^{3,13-17}$. Arora et al. $^{3}$ evaluated the degumming of CPO and crude palm olein with a hexane solvent to remove phospholipids, Lovibond color value, carotenoids, major tocopherols and tocotrien- 
ols, and major fatty acids. Ong et al. ${ }^{13}$ studied ultrafiltration (UF) of CPO degumming for the removal of phospholipids, carotenes, Lovibond color, FFAs, and volatile matter. Lai et al. ${ }^{14}$ performed research on the deacidification of a model fatty system of $\mathrm{CPO}$ using various solvents and nanofiltration. On the other hand, polyvinylidene fluoride (PVDF) has been modified with polyvinyl alcohol (PVA) crosslinked as a UF membrane in the deacidification of $\mathrm{CPO}^{15}$. Deacidification of $\mathrm{CPO}$ using an aqueous $\mathrm{NaOH}$ solution in a hollow fiber membrane contactor was carried out by Purwasasmita et al. ${ }^{16}$ Furthermore, a hexane solvent combined with a UF membrane has been applied to remove phospholipids from residual palm oil fibers ${ }^{17}$.

Similar molecular weights of TAGs and phospholipids (about 900 and $700 \mathrm{Da}$, respectively) can interfere with their separation process using membrane technology. Phospholipids tend to form reverse micelles in nonpolar media like hexane or crude oil because of their amphiphilic properties ${ }^{18,19}$. This unique feature of phospholipid micelles increases their average molecular weight from $700 \mathrm{Da}$ to around $20 \mathrm{kDa}$ or even more ${ }^{12}$, which is significantly different from TAGs. As a result, the UF membrane is able to separate the micelles from the solvent-oil mixture, and the phospholipids are retained by the UF membrane ${ }^{20}$. However, the primary challenge in the use of membranes, especially UF, is the existence of a phenomenon called fouling. Fouling is an irreversible membrane change that is caused by specific physical and chemical interactions between the membrane and the various components present in the process flow. Membrane fouling is represented by a decrease in the permeate flux due to the effect of blocking on the surface as well as inside the membrane pores ${ }^{21,22}$. As it is essential to have a detailed investigation on fouling and there is no research investigating membrane fouling in the degumming of crude palm oil, this research is focused primarily on studying the flux decline as well as the fouling mechanism in the degumming of CPO by UF.

Fundamental studies on fouling mechanisms on UF membranes have been performed for coconut cream $^{23}$, organic compounds ${ }^{24}$, whey models ${ }^{25}$, and polyethylene glycol (PEG) ${ }^{26}$. In more detail, the fundamental studies focusing on the fouling mechanism in UF for oil degumming or separation of oil components are limited only for degumming corn oil ${ }^{18-27}$, crude sunflower oil, and soybean oil ${ }^{14}$. This study placed emphasis on the fundamental and comprehensive analysis of the influence of oil solvents and micelles on fouling mechanism models. Specifically, this study addressed a novelty finding in the analysis of the fouling model and fouling mechanism in UF for degumming CPO.

\section{Materials and methods}

\section{Materials}

The main raw materials used in this experiment were CPO (Kalimantan, Indonesia) and isopropanol (Merck) as a solvent. The UF membrane was a laboratory-made polyethersulfone (PES) flat-sheet membrane. The PES material was Veradel PESU 3100P (Solvay, Singapore). The membrane was prepared via a non-solvent-induced phase separation method with PEG as the additive and N-methyl-2-pyrrolidone (NMP) as the solvent ${ }^{28}$.

\section{Membrane characterization}

The membrane was characterized for its molecular weight cut-off (MWCO), contact angle, permeability, surface structure, and specific functional groups. The MWCO of the membrane represents the lowest molecular weight of solute (in Daltons), in which $90 \%$ of the solute is rejected by the membrane. The MWCO value is evaluated to describe the pore size distribution and retention capabilities of membranes. In this work, solute rejection experiments were performed using PEG (from SigmaAldrich) as polymer solute with various molecular weights (MWs) of 2, 6, 12, 20 and $35 \mathrm{kDa}$. The PEG solution was prepared in $1 \mathrm{wt} . \%$ concentration and then filtrated in a dead-end filtration cell. The permeate samples were analyzed using a digital handheld refractometer (PAL-91S, ATAGO, Japan). Plots of MW versus solute rejection were created, and then the MW corresponding to $90 \%$ rejection was estimated as MWCO of the membrane. The hydrophobic/hydrophilic character of the membrane was determined by measuring the water-membrane contact angle $(\theta)$. The water-membrane contact angle values of the prepared membrane were measured using water contact angle meter (RACE contact angle meter, Japan) using deionized water as a probe liquid.

Membrane permeability was evaluated by determining the membrane flux of distilled water or isopropanol in the membrane module at various operating pressures (1-3 bar). The fluxes were calculated according to the sample volume $(V)$, the sampling time $(t)$, and the membrane surface area $(A)$. The volumetric permeate flow rate $(Q)$ was calculated by

$$
Q=\frac{V}{t}
$$

Further, the flux $(J)$ was determined by:

$$
J=\frac{1}{A} \cdot Q
$$


The membrane's surface and the cross-sectional structure were characterized using scanning electron microscopy (SEM, FEI Type Inspect-S50). The specific functional groups of the membrane were determined using FTIR Spectroscopy (Prestige-21, Shimadzu, Japan).

\section{Evaluation of UF membrane performance for degumming of the CPO-isopropanol mixture}

The UF performance was examined using laboratory-made cell filtration based on the total recycle model as illustrated in Fig. 1.

The cell filtration was equipped with a centrifugal pump (Kemflow, with nominal flow rate 1.0 LPM, maximum pump output of 7.58 bar, maximum inlet pressure of 4.14 bar) as the feed pump, gate valves, pressure gauge (JAKO, with maximum pressure of 10.34 bar) and a stainless steel ultrafiltration housing. The total recycle model involved returning the permeate and retentate flow back to the feed tank to maintain equivalent concentration during the process. All experimental runs were conducted at room temperature $\left(29 \pm 2{ }^{\circ} \mathrm{C}\right)$. Before starting the experiments, membranes were first compacted by filtering water through the membrane at a pressure of 1 bar for $60 \mathrm{~min}$. For each run, a new circular membrane sheet with an effective area of $13.85 \mathrm{~cm}^{2}$ was used.

A micellar solution was prepared by mixing $\mathrm{CPO}$ with isopropanol with ratios of CPO of $30 \%$, $40 \%, 50 \%$, and $60 \%$ weight of the solution. The filtration cell was operated at 1 bar for $120 \mathrm{~min}$, and before returning it back to the feed tank, the permeate was collected every $5 \mathrm{~min}$ to determine the flux and concentration of phospholipids/fatty acids. The feed temperature was varied $-30{ }^{\circ} \mathrm{C}, 35^{\circ} \mathrm{C}, 40^{\circ} \mathrm{C}$, and $45^{\circ} \mathrm{C}$ - in order to investigate the effect of temperature on UF performance. The feed tank was equipped with a temperature regulator and a magnetic stirrer for homogenization of oil micelles. Membrane performance was evaluated in terms of

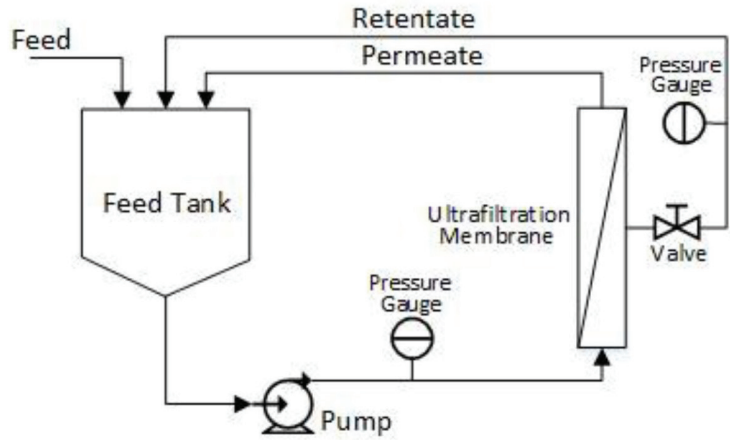

Fig. 1 - Schematic of ultrafiltration cell with total recycle operation permeate flux and phospholipid/FFA rejection. Permeate fluxes $(J)$ were determined by weighing the volume of the permeate collected at 5-min intervals for $120 \mathrm{~min}$ and calculated using

$$
J=\frac{W}{A \cdot t}
$$

Where $W$ represents the total weight of the permeate, $A$ is the membrane area, and $t$ is the time interval.

Rejection of phospholipids and FFAs was determined on the basis of the concentration of phospholipids/FFAs in the feed $\left(C_{f}\right)$ and in the permeate $\left(C_{p}\right)$. Rejection is calculated according to

$$
R=\frac{C_{f}-C_{p}}{C_{f}}
$$

\section{Characterization of CPO and permeate}

The specific characteristics of CPO and permeate included the phospholipid and FFA content. Phospholipids were expressed as total phosphorus and analyzed according to the AOAC $\mathrm{Ca} 12-55$ method. Determination of FFA was performed via the acid-base titration method ${ }^{14}$.

\section{Blocking mechanism}

The blocking mechanism of CPO-isopropanol UF was studied according to Hermia's model. This model has been previously applied for the evaluation of the fouling mechanism of dye solution $\mathrm{UF}^{28}$, konjac glucomannan separation ${ }^{29}$, and UF of model dye wastewater ${ }^{30}$. Hermia's model describes the mechanism of membrane fouling on the basis of the blocking filtration law, consisting of complete pore blocking, standard pore blocking, and intermediate pore blocking and cake filtration. The blocking law filtration is expressed in terms of permeation time and filtration time, and was developed for dead-end filtration as shown $\mathrm{in}^{31}$ :

$$
\frac{\mathrm{d}^{2} t}{\mathrm{~d} V^{2}}=k\left(\frac{\mathrm{d} t}{\mathrm{~d} V}\right)^{n}
$$

where $t$ is the filtration time, $V$ is the permeate volume, $k$ is a constant, and $n$ is a value illustrating the different fouling mechanisms.

The values of $n$ are described as follows: complete blocking with $n=2$, intermediate blocking with $n=1$, standard blocking with $n=1.5$, and cake layer formation with $n=0$. In the complete blocking model, it is assumed that each solute participated in blocking the entrance of the membrane pores completely. In intermediate blocking, it is assumed that every solute stays on the previously deposited 
solutes. Standard blocking considers the deposition of each solute on the internal pore wall. The cake layer formation occurs due to the accumulation of the solute on the membrane surface in a cake form ${ }^{32}$. Hermia's model was then linearized on the basis of the $n$ value for each model by fitting equations (6) to (9) regarding the permeate flux versus time, as presented in the following.

For Complete Blocking $(n=2)$ :

$$
\ln J=\ln J_{0}-k_{c} t
$$

For Intermediate Blocking $(n=1)$ :

$$
\frac{1}{J}=\frac{1}{J_{0}}+k_{i} t
$$

For Standard Blocking $(n=1.5)$ :

$$
\frac{1}{\sqrt{J}}=\frac{1}{\sqrt{J_{0}}}+k_{s} t
$$

For Cake/Layer Formation $(n=0)$ :

$$
\frac{1}{J^{2}}=\frac{1}{J_{0}^{2}}+k_{c f} t
$$

Here, $k_{c}, k_{i}, k_{s}$, and $k_{c f}$ are constants for complete blocking, intermediate blocking, standard blocking, and cake layer formation, respectively.

\section{Results and discussion}

\section{Membrane characteristics}

Table 1 shows the characterization results of the synthesized membranes confirming PEG rejections, MWCO, contact angle, and permeabilities.

Details of the water and isopropanol flux profiles at various pressures for the UF membrane are presented in Fig. 2.

Table 1 - Characteristics of the synthesized PES membrane

\begin{tabular}{cc}
\hline Parameter & \\
\hline Rejection of 2 kDa PEG (R) & $9.83 \%$ \\
Rejection of 6 kDa PEG (R) & $13.11 \%$ \\
Rejection of 12 kDa PEG (R) & $68.85 \%$ \\
Rejection of 20 kDa PEG (R) & $88.52 \%$ \\
Rejection of 35 kDa PEG (R) & $96.72 \%$ \\
MWCO & $25 \mathrm{kDa}$ \\
Contact angle $(\theta)$ & $63.63^{\circ}$ \\
Water permeability $\left(L_{\mathrm{h}, \mathrm{w}}\right)$ & $42.77 \mathrm{~L} \mathrm{~m}^{-2} \mathrm{~h}^{-1}$ \\
Isopropanol permeability $\left(L_{\mathrm{h}, \mathrm{sp}}\right)$ & $63.58 \mathrm{~L} \mathrm{~m}^{-2} \mathrm{~h}^{-1}$ \\
\hline
\end{tabular}

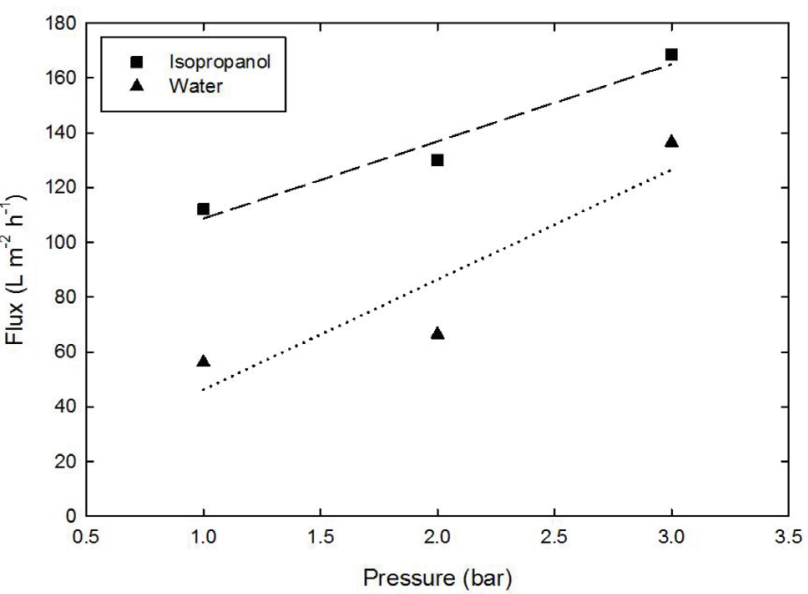

Fig. 2 - Flux profile of isopropanol and water at pressure of 1-3 bar

The figure shows an increase in water and isopropanol flux with the rise of pressure from 1 to 3 bar. According to the linearization regression $(y=m x)$ of water and isopropanol flux in the figure, it was found that the water permeability and isopropanol permeability were $42.77 \mathrm{~L} \mathrm{~m}^{-2} \mathrm{~h}^{-1}$ and $63.58 \mathrm{~L} \mathrm{~m}^{-2} \mathrm{~h}^{-1}$, respectively. This is surprising, since water is predicted to have permeability higher than that of ethanol which is why water is the most polar solvent. This result is in contrast with de Melo et al. ${ }^{33}$, confirming that lower solvent polarity results in a decrease in permeation. In addition, the prepared PES membrane had the characteristics of hydrophilic membranes represented by the contact angle value as listed in Table 1, especially because of the addition of polyvinylpyrrolidone (PVP) and $\mathrm{PEG}^{34}$. With the hydrophilic characteristic of the PES membrane, water permeation is expected to be higher than that of isopropanol. Solvent characteristics, such as viscosity, surface tension, and polarity, as well as the molar volume of the solvent, have an effect on the transport of the solvent by the membrane $^{35-36}$. According to the physicochemical characteristics of the solvent (viscosity and interfacial tension), the isopropanol flux should be below the water flux. However, this phenomenon was not observed in this research, presumably because there wasa specific interaction between the membrane and the solvent. A similar result was observed by Araki et al. ${ }^{37}$ The high permeability of isopropanol indicates that the conditioning process (immersing in isopropanol) created a less hydrophilic PES membrane. The alteration of the hydrophobic characteristic is caused by the transformation of the hydrophilic and hydrophobic sites of the membrane, resulting in the higher permeability of isopropanol. Water permeation is correlated to the hydrophilic characteristic (hydrogen bond formation) of the membrane. When an alcohol such as isopropanol is permeated, the hydrogen bond formation becomes less, contributing to a low water flux. 


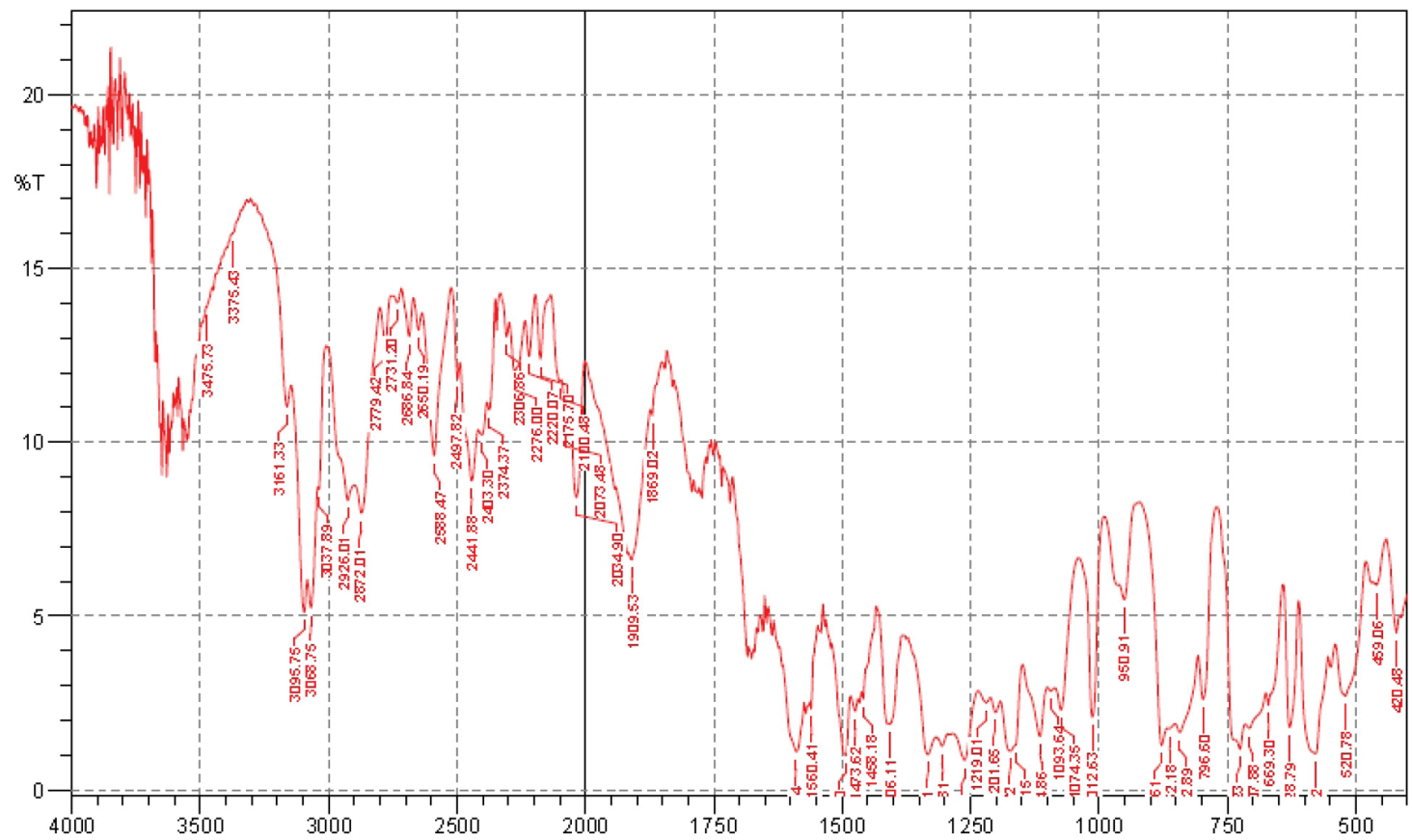

Fig. 3 -FT-IR spectra of the membrane confirming specific functional groups

\section{Specific functional groups}

Specific functional groups of the membrane are shown in Fig. 3.

According to the figure, characteristics of the PES membrane are determined by peaks at 1492.9 and $1589.3 \mathrm{~cm}^{-1}$. Moreover, the peaks of 1161.15 and $1172.7 \mathrm{~cm}^{-1}$ show a symmetric stretching sulfur $\mathrm{SO}_{2}$. In more detail, Table 2 lists other specific functional groups of the membrane.

Based on the table, the specific functional groups were matched with the chemical structure of main membrane materials. Beside the PES characteristic, the $\mathrm{O}-\mathrm{H}$ bonding vibration, $\mathrm{C}-\mathrm{H}$ asymmetric, $\mathrm{C}-\mathrm{C}$ stretching in benzene ring and $-\mathrm{C}-\mathrm{O}-\mathrm{C}$ bonding are representation of bonds in the polymer of PEG.

\section{Permeate flux}

The profile of the permeate flux showing flux versus time is presented in Fig. 4.

The figure shows that there is a flux decline during the filtration of the solvent and CPO mixtures. A significant flux fall-off was observed during the first 5 min of filtration, followed by a flux reduction deceleration rate, and then finally the flux became steady. A three-step behavior was also perceived by Penha et al. ${ }^{38}$ during the filtration of maracuja oil $/ n$-hexane mixture. The initial flux decline is caused by a phenomenon called polarization concentration, whereas the following flux reduction is a result of membrane fouling. Comparable performances were reported for oil/hexane mixture per-

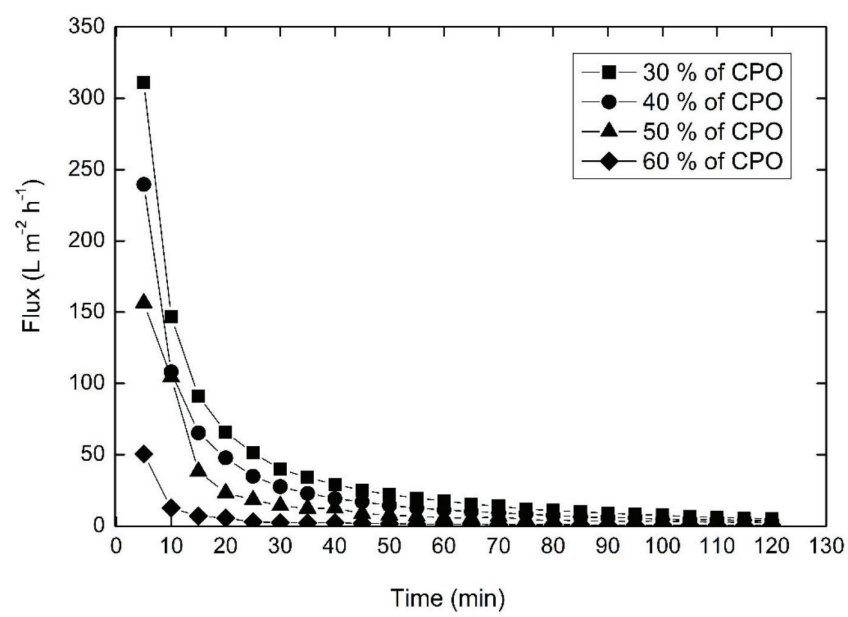

Fig. 4 -Permeate flux profile in the UF of the CPO-isopropanol mixture at various concentrations of CPO (feed temperature: $29^{\circ} \mathrm{C}$, transmembrane pressure: 1 bar)

Table 2 - Specific functional groups as shown in FT-IR spectra

\begin{tabular}{cc}
\hline Absorbance peaks $\left(\mathrm{cm}^{-1}\right)$ & Specific functional groups \\
\hline 1473.41 and 1560.62 & $\begin{array}{c}\text { Aromatic compounds } \\
\text { (C-C stretching) }\end{array}$ \\
1219.01 and 1261.4 & Aromatic ether compounds \\
849.2 and 862.2 & Para substituted benzene \\
$1074.3,1093.6$ and 1114.8 & -C-O-C- bonding \\
2872.01 and 2926.01 & C-H asymmetric bonding \\
3375.43 and 3475.73 & O-H alcohol bonding \\
\hline
\end{tabular}




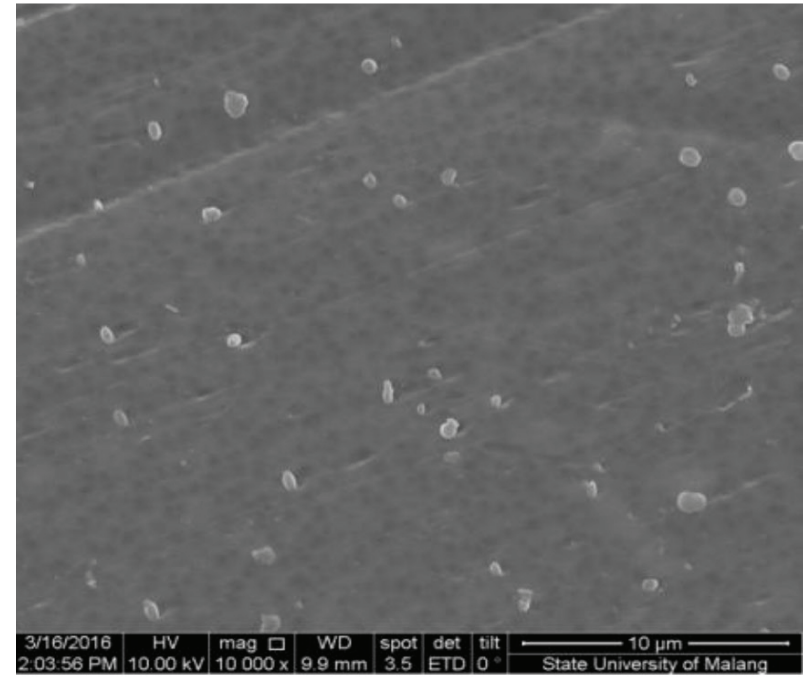

(1a)

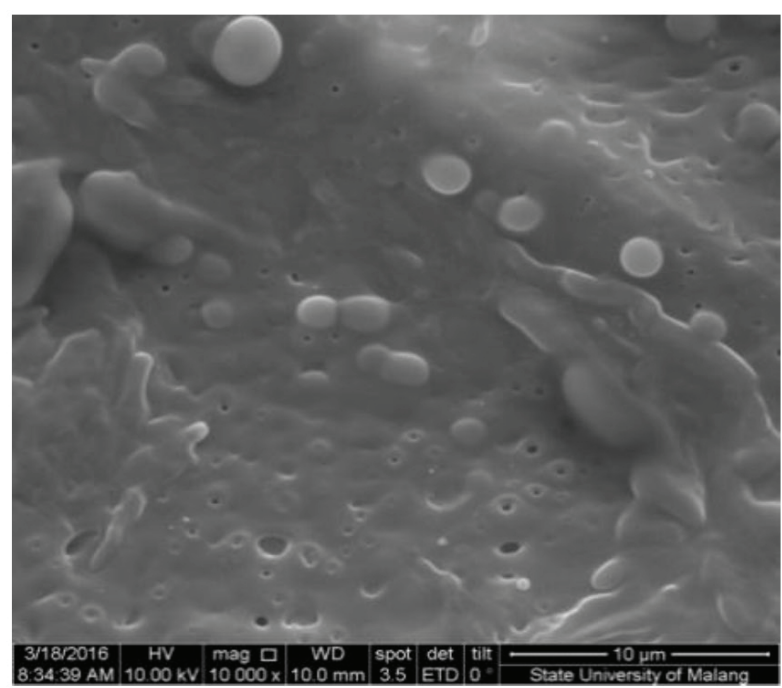

(1b)

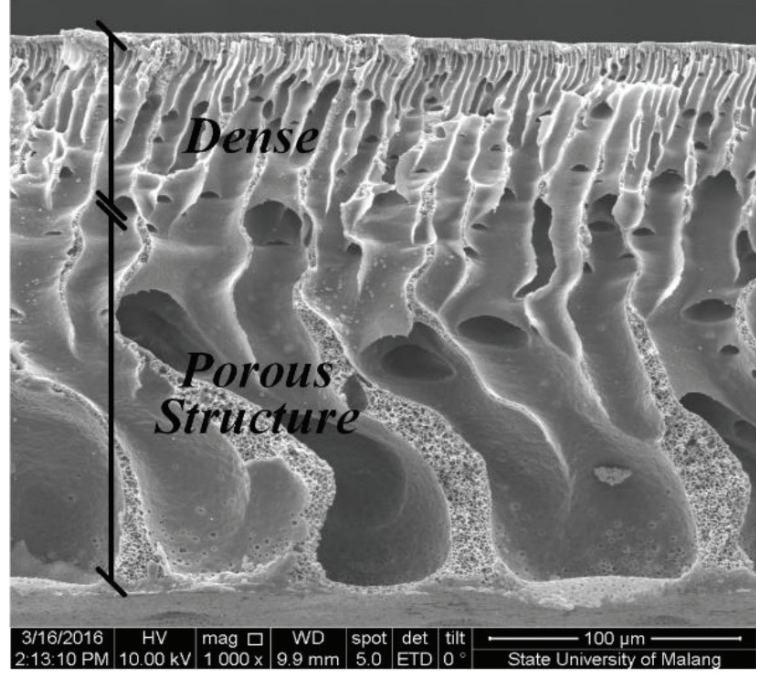

(2a)

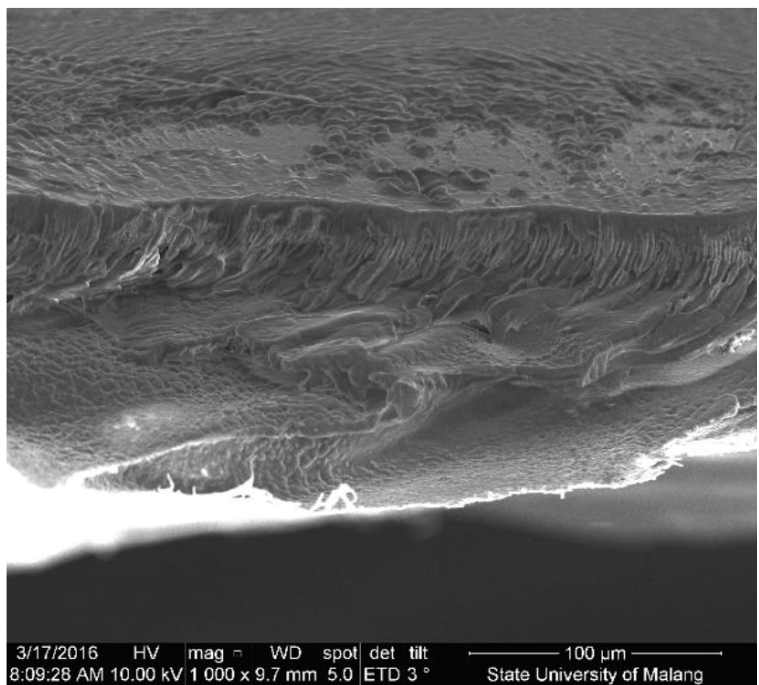

(2b)

Fig. 5 - SEM images at magnification of 10,000x: ('lean membranes (1a-Surface), (2a-Cross-sectional structure) and fouled membrane after ultrafiltration of $30 \%$ CPO-solvent mixture (1b-Surface), (2b-Cross-sectional structure)

meation through the UF membrane using sunflower oil $^{39}$ as well as coconut oil, groundnut oil, mustard oil, sunflower oil, and rice bran oil ${ }^{36-40}$. In addition, it was reported that the flux reduction at the beginning of the sunflower oil- $n$-hexane filtration was type of concentration polarization phenomenon and gel layer formation on the membrane surface ${ }^{39}$. Moreover, the flux drop at the end of the filtration was due to the deposition of a gel on the membrane surface $^{38,41,42}$. The deposited layer is formed because of the phospholipids retained on the membrane surface and pores plugging ${ }^{14,43}$.

Fig. 4 also confirms that the increase in oil concentration leads to a higher reduction in flux. This decrease takes place due to an increase in oil concentration, resulting in the increase insolution viscosity. With the rise of viscosity, a smaller flux is obtained since the permeability is influenced by the viscosity $^{35}$. In addition, a lower flux is obtained as a result of polarized/gel layer formation. When the oil concentration is higher, the layer becomes larger and generates larger resistance to the flux permeation $^{33,36,41}$. As elucidated by Kim et al. ${ }^{41}$, convective solute transport to the membrane produces a sharp gradient of concentration inside the boundary layer. Because of diffusion, solute back-transport into the bulk takes place, and a close-packed arrangement of the solute is formed. As a consequence, no more solute can be accommodated, and the mobility of solutes is restricted.

Scanning electron microscopy images of the fouled membrane, as displayed in Fig. 5, confirm that a foulant layer on the membrane's surface is present. 


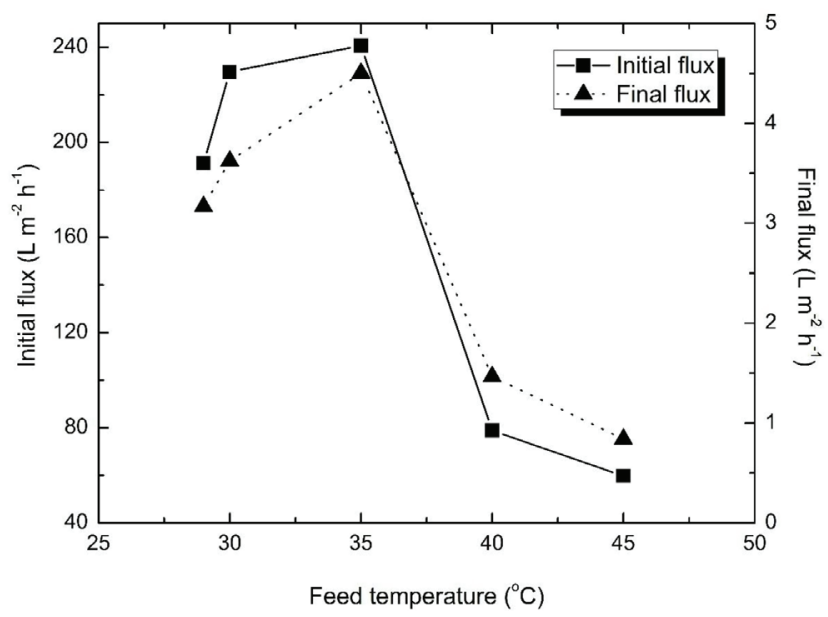

Fig. 6 - Effect of feed temperature on the initial and final flux at a pressure of 1 bar and CPO concentration of $30 \%$

Fig. 6 displays the effect of feed temperature on the initial and final permeate flux.

The figure suggests that the increase in the mixture temperature from 29 to $35^{\circ} \mathrm{C}$ had an effect on the higher flux permeate. This was expected due to the decrease in viscosity or the increase in phospholipid diffusion on the membrane pores. However, a further temperature increase (from 40 to $45{ }^{\circ} \mathrm{C}$ ) ledto a decrease in flux, but the reduction in viscosity had no effect on the flux. This result is close to that of Kim et $a l^{41}$, confirming that the operating temperature of $40{ }^{\circ} \mathrm{C}$ was suitable for the degumming of soybean extract; above the temperature of $40^{\circ} \mathrm{C}$, the flux decreased. A decline in flux is predicted because of the fouling on the membrane surface as a result of solid denaturation or gelatinization, as well as insoluble salts precipitation at a high temperature ${ }^{44}$.

\section{Phospholipid and FFA rejection}

Membrane selectivity is represented as rejection, indicating the membrane's ability to reject or remove a feed compound. Micelles are formed when phospholipids are dispersed in water. The mixture of phospholipids in a nonpolar solvent such as isopropanol formed reverse micelles having an average molecular weight of 20,000 Daltons (10 $200 \mathrm{~nm})^{44}$. Based on the pore size, UF rejects compounds having a molecular weight in the range of 300-500,000 Daltons. Hence, in the phospholipids-isopropanol system, phospholipids are expected to be retained in the retentate, and the permeate comprises the oil and isopropanol. In contrast to phospholipids, the MWs of FFAs and TAGs are similar. TAGs and FFAs have a molecular weight of $800 \mathrm{Da}$ and $300 \mathrm{Da}$, respectively ${ }^{9}$. Compared to the UF pore size, the separation of FFAs is challenging due to the low selectivity, and it results in a low rejection value. Rejection of phospholipids and FFAs at various CPO concentrations is displayed in Table 3.
Table 3 -Rejection of phospholipid and fatty acids at various CPO concentrations at a pressure of 1 bar and feed temperature of $30^{\circ} \mathrm{C}$

\begin{tabular}{c|c|c}
\hline CPO concentration & $\begin{array}{c}\text { Phospholipid } \\
\text { rejection (\%) }\end{array}$ & $\begin{array}{c}\text { Free fatty acid } \\
\text { rejection (\%) }\end{array}$ \\
\hline $30 \%$ & $>99.21$ & 16.13 \\
$40 \%$ & 92.93 & 12.93 \\
$50 \%$ & 37.52 & 9.09 \\
\hline
\end{tabular}

Table 4 -Rejection of phospholipid and fatty acids at various feed temperatures at a pressure of 1 bar and CPO concentration of $30 \%$

\begin{tabular}{c|c|c}
\hline Temperature & $\begin{array}{c}\text { Phospholipid } \\
\text { rejection (\%) }\end{array}$ & $\begin{array}{c}\text { Free fatty acid } \\
\text { rejection (\%) }\end{array}$ \\
\hline $30{ }^{\circ} \mathrm{C}$ & $>99.21$ & 16.13 \\
$35^{\circ} \mathrm{C}$ & 86.60 & 7.17 \\
$40^{\circ} \mathrm{C}$ & 73.94 & 10.24 \\
\hline
\end{tabular}

The table shows that rejection of phospholipids is significantly higher than that of fatty acids. This is noticeable since the molecular weight of micelle phospholipids is considerably greater than that of FFAs. The phospholipids' rejection is found to be greater than $99 \%$ at a CPO concentration of $30 \%$, and slightly reduced to nearly $93 \%$ with the increase in CPO concentration to $40 \%$. The reduction of phospholipid rejection becomes more obvious with the increase in CPO concentration to $50 \%$. In addition, a similar trend is shown when the feed temperature is raised. The rejection of both phospholipids and FFAs declines at higher temperatures from $30{ }^{\circ} \mathrm{C}$ to $40{ }^{\circ} \mathrm{C}$, as presented in Table 4 .

\section{Blocking mechanism by Hermia's model}

In this research, Hermia's model was applied in order to evaluate the blocking mechanism during UF of the CPO-isopropanol mixture at various feed $\mathrm{CPO}$ concentrations. The fouling mechanism represented by the blocking mechanism is identified by fitting the experimental data into Hermia's linearized equation (equations (4) to (7)). The fitting of experimental data to the four-type Hermia model is shown in Fig. 7, and the corresponding correlation coefficients $\left(R^{2}\right)$ are listed in Table 5.

According to the table, two dominant blocking mechanisms are found: standard blocking and intermediate blocking. At low concentrations of $\mathrm{CPO}$ ( $30 \%$ and $40 \%$ ), the blocking mechanism is dominated by standard blocking. In contrast, at higher concentrations of CPO (50\% and $60 \%)$, the intermediate blocking is the dominant mechanism. Standard blocking assumes that each solute is deposited into the internal pore wall. In intermediate blocking, 


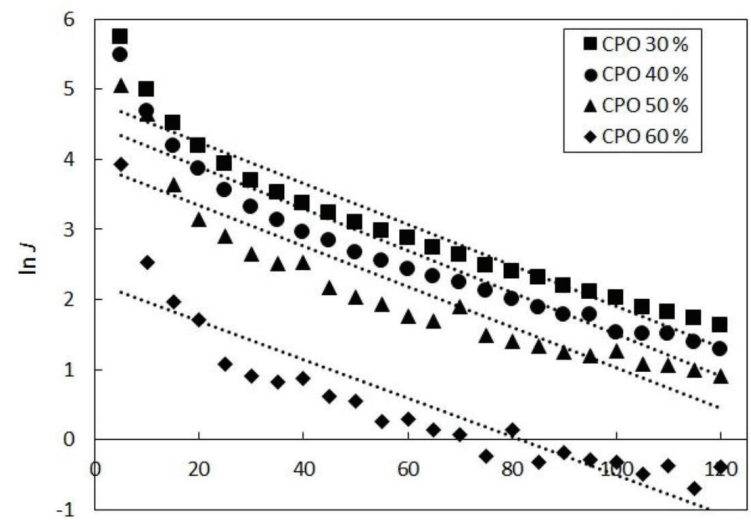

Time ( $\min )$

(a)

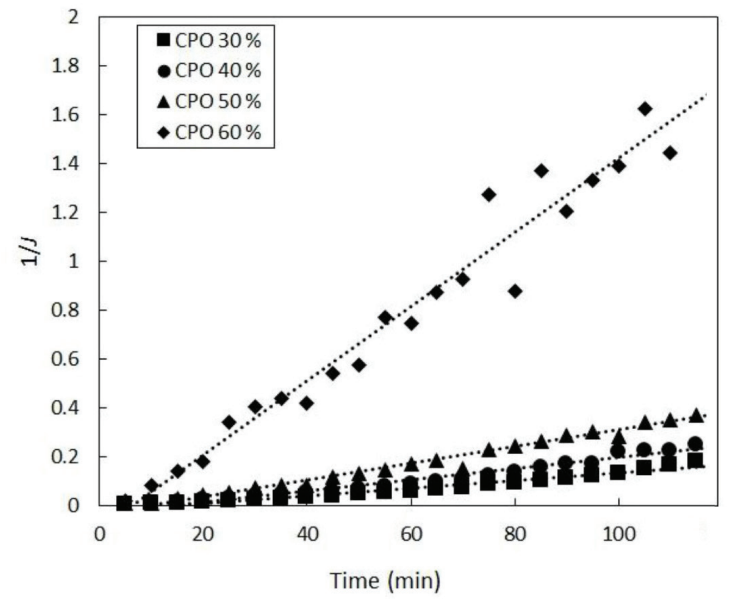

(c)

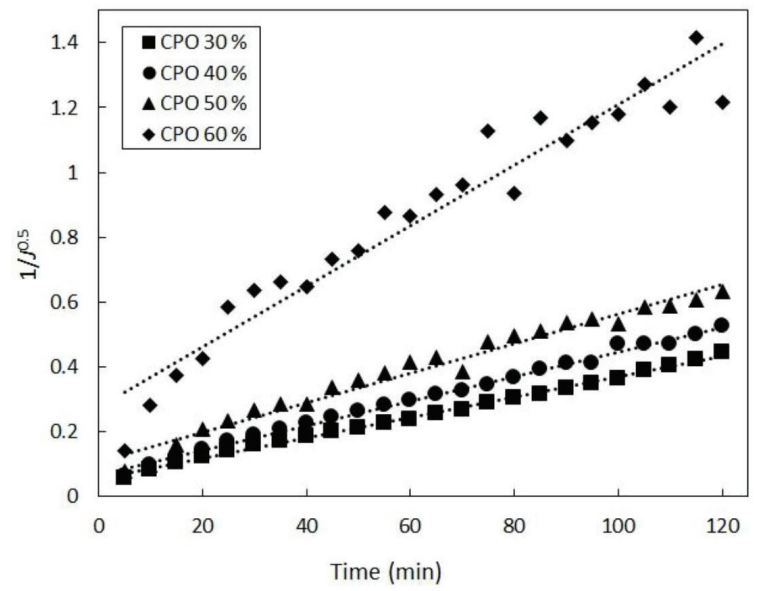

(b)

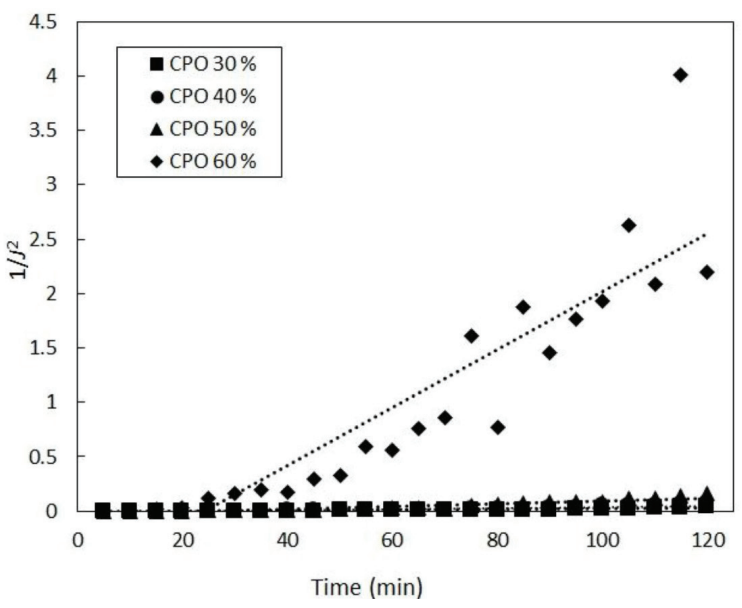

(d)

Fig. 7 - Fitting of experimental data (feed temperature: $30{ }^{\circ} \mathrm{C}$, pressure: 1 bar) to Hermia's model: (a) complete blocking, (b) standard blocking, (c) intermediate blocking, and (d) cake/gel layer formation

Table $5-R^{2}$ values of the blocking mechanism based on Hermia's model

\begin{tabular}{c|c|c|c|c}
\hline \multirow{2}{*}{$\begin{array}{c}\text { Feed } \\
\text { concentration }\end{array}$} & \multicolumn{4}{|c}{$R^{2}$} \\
\cline { 2 - 5 } & $\begin{array}{c}\text { Complete } \\
\text { blocking }\end{array}$ & $\begin{array}{c}\text { Intermediate } \\
\text { blocking }\end{array}$ & $\begin{array}{c}\text { Standard } \\
\text { blocking }\end{array}$ & $\begin{array}{c}\text { Cake/Gel } \\
\text { formation }\end{array}$ \\
\hline CPO 30\% & 0.9186 & 0.9512 & 0.9971 & 0.7755 \\
CPO 40\% & 0.9022 & 0.9618 & 0.9953 & 0.8053 \\
CPO 50\% & 0.8354 & 0.9811 & 0.9737 & 0.8769 \\
CPO 60\% & 0.7797 & 0.9432 & 0.9394 & 0.8052 \\
\hline
\end{tabular}

it is proposed that every solute remains on the previously deposited solutes.

The proposed standard blocking and intermediate blocking mechanisms in UF of CPO-isopropanol are illustrated in Fig. 8.

According to Fig. 8(a), the large particles that accumulated on the membrane surface and blocked the membrane pores were TAGs. The large particles that formed at a high concentration of CPO were first presumed to be phospholipid-isopropanol micelles because of their large size and potential to block the pores. However, this assumption is in contradiction with phospholipid rejection. If the large particles were an agglomeration of phospholipid micelles, then rejection at high CPO concentrations should be greater. Hence, it can be assumed that, at high concentrations of CPO, not all phospholipids generate micelles with isopropanol. This confirms why phospholipid rejection at high concentrations of $\mathrm{CPO}$ was lower. Hence, the larger particles that accumulated on the membrane surface were predicted to be other oil compounds such as TAGs.

In addition, Fig. 8(b) shows that, at low concentrations of $\mathrm{CPO}$, the dominant fouling mechanism was standard blocking, representing small particles attached inside the membrane pore, and causing pore constriction (reduction in pore size). The compound that was possibly blocking the membrane pores was fatty acid, since fatty acids are smaller than phospholipid-isopropanol micelles. At 


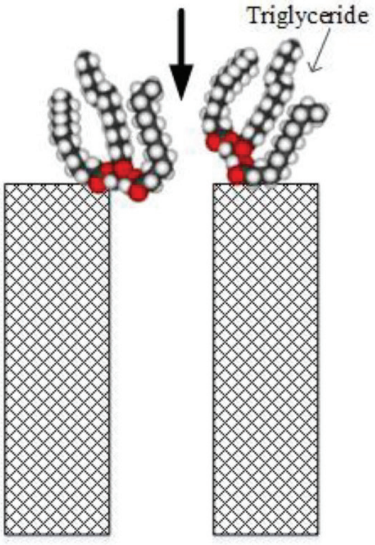

(a)

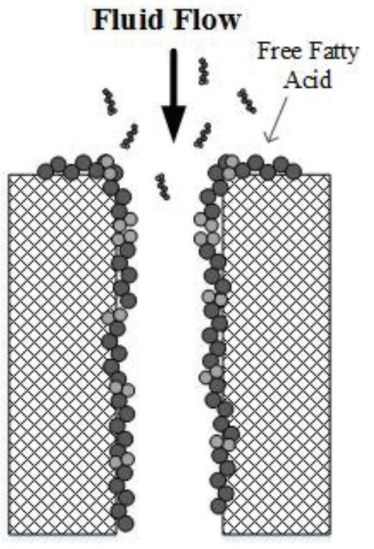

(b)
Fig. 8 - Schematic illustration of (a) intermediate blocking and (b) standard blocking mechanisms in UF of the CPO-isopropanol mixture

low concentrations of CPO, a sufficient amount of phospholipid-isopropanol micelles was formed, with pore constriction providing high rejection of phospholipids. On the other hand, small molecules, such as fatty acids, can enter the membrane pores.

\section{Conclusions}

Phospholipids separation and FFAs removal in CPO have been performed using a PES UF membrane. In general, lower fluxes were obtained with the increase in $\mathrm{CPO}$ concentration. Raising the feed temperature from $30{ }^{\circ} \mathrm{C}$ to $40{ }^{\circ} \mathrm{C}$ resulted in a lower permeate flux, but further feed temperature increase to $45{ }^{\circ} \mathrm{C}$ decreased the permeate flux. The phospholipid rejection rate was in the range 93-99 \%. However, the removal of fatty acids was unsuccessful. The decrease in flux due to membrane fouling was evaluated on the basis of Hermia's model, confirming that there were two dominant mechanisms observed: standard blocking and intermediate blocking.

\section{ACKNOWLEDGEMENTS}

Luh Astla Diva Savitri and Asih Mustika Sari were appreciated for their valuable research assistance. NA acknowledges the Directorate of Research and Community Service, Ministry of Research and Higher Technology, the Republic of Indonesia for the financial support. The research was funded by the Fundamental Research Grant.

\section{References}

1. Subramanian, R., Nakajima, M., Raghavarao, K. S., Kimura, $T$., Processing vegetable oils using nonporous denser polymeric composite membranes, J. Am. Oil Che. Soc. 81(4) (2004) 313.

doi: https://doi.org/10.1007/s11746-004-0901-z
2. Mba, O. I., Dumont, M. J., Ngadi, M., Palm oil: Processing, characterization and utilization in the food industry-A review, Food Biosci. 1 (2015) 26. doi: https://doi.org/10.1016/j.fbio.2015.01.003

3. Arora, S., Manjula, S., Krishna, A. G., Subramanian, R., Membrane processing of crude palm oil, Desalination 191(1-3) (2006) 454 doi: https://doi.org/10.1016/j.desal.2005.04.129

4. Basiron, Y., Palm oil production through sustainable plantations, Eur. J. Lipid Sci. Technol. 109(4) (2007) 289. doi: https://doi.org/10.1002/ejlt.200600223

5. Banu, M., Siddaramaiah, Prasad, N., Radical scavenging activity of tertiary butyl hydroquinone and assessment of stability of palm oil (Elaeis guineensis) by ultrasonic studies, Chem. Biochem. Eng. Q. 30(4) (2016) 477. doi: https://doi.org/10.15255/CABEQ.2015.2185

6. Edem, D. O., Palm oil: Biochemical, physiological, nutritional, haematological and toxicological aspects: A review, Plant Foods Human Nutr. 57(3-4) (2002) 319. doi: https://doi.org/10.1023/A:1021828132707

7. Sarip, M. S., Morad, N. A., Yamashita, Y., Tsuji, T., Yunus, M. A., Aziz, M. K., Lam, H. L., Crude palm oil (CPO) extraction using hot compressed water (HCW), Sep. Purif. Technol. 169 (2016) 103. doi: https://doi.org/10.1016/j.seppur.2016.06.001

8. Wang, T., Soybean Oil, in Gunstone. F. (Ed.), Vegetable Oils in Food Technology: Composition, Properties and Uses, $2^{\text {nd }}$ Ed., John Wiley \& Sons Ltd., Chichester, pp 59-98.

9. Fornasero, M. L., Marenchino, R. N., Pagliero, C. L., Deacidification of soybean oil combining solvent extraction and membrane technology, Adv. Mater. Sci. Eng. 4 (2013) 1. doi: https://doi.org/10.1155/2013/646343

10. Liu, K. T., Liang, F. L., Lin, Y. F., Tung, K. L., Chung, T. W., $H s u, S$. H., A novel green process on the purification of crude Jatropha oil with large permeate flux enhancement, Fuel 111 (2013) 180. doi: https://doi.org/10.1016/j.fuel.2013.04.049

11. de Morais, Coutinho, C., Chiu, M. C., Basso, R. C., Ribeiro, A. P., Gonçalves, L. A, Viotto, L. A., State of art of the application of membrane technology to vegetable oils: A review, Food Res. Int.42(5) (2009) 536. doi: https://doi.org/10.1016/j.foodres.2009.02.010

12. Ladhe, A. R., Kumar, N. K., Application of membrane technology in vegetable oil processing, Memb. Technol. 23 (2010) 63 . doi: https://doi.org/10.1016/B978-1-85617-632-3.00005-7

13. Ong, K. K., Fakhru'l-Razi, A., Baharin, B. S., Hassan, M. A., Degumming of crude palm oil by membrane filtration, Artif. Cells Blood Substit. Immobil. Biotechnol. 27(5-6) (1999) 381. doi: https://doi.org/10.3109/10731199909117707

14. Lai, S. O., Heng, S. L., Chong, K. C., Lau, W. J., Deacidification of palm oil using solvent extraction integrated with membrane technology, Jurnal Teknologi 78(12) (2016) 69. doi: https://doi.org/10.11113/jt.v78.10069

15. Azmi, R. A., Goh, P. S., Ismail, A. F., Lau, W. J., Ng, B. C., Othman N. H., Noor, A. M., Yusoff, M. S. A., Deacidification of crude palm oil using PVA-crosslinked PVDF membrane, J. Food Eng. 166 (2015) 165. doi: https://doi.org/10.1016/j.jfoodeng.2015.06.001

16. Purwasasmita, M., Nabu, E. B. P., Khoiruddin, Wenten, I. $G$., Non-dispersive chemical deacidification of crude palm oil in hollow fiber membrane contactor, J. Eng. Technol. Sci. 47(4) (2015) 426. doi: https://doi.org/10.5614/j.eng.technol.sci.2015.47.4.6 
17. Majid, R. A., Mohamad, A. W., May, C. Y., Performance of polymeric membranes for phospholipid removal from residual palm fibre oil/hexane miscella, J. Oil Palm. Res. 25(2) (2013) 253.

18. Ochoa, N., Pagliero, C., Marchese, J., Mattea, M., Ultrafiltration of vegetable oils: Degumming by polymeric membranes, Sep. Purif. Technol. 22 (2001) 417. doi: https://doi.org/10.1016/S1383-5866(00)00178-7

19. Liu, K.-T., Liang, F.-L., Lin, Y.-F., Tung, K.-L., Chung, T.$W$., Hsu, S.-H., A novel green process on the purification of crude Jatropha oil with largepermeate flux enhancement, Fuel. 111 (2013) 180. doi: https://doi.org/10.1016/j.fuel.2013.04.049

20. Cheryan, M., Membrane technology in the vegetable oil industry, Memb. Technol. (2005) 5.

21. Said, M., Ahmad, A., Mohammad, A. W., Nor, M. T. M., Abdullah, S. R. S., Blocking mechanism of PES membrane during ultrafiltration of POME, J. Ind. Eng. Chem. 21 (2015) 182. doi: https://doi.org/10.1016/j.jiec.2014.02.023

22. Shi, X., Tal, G., Hankins, N. P., Gitis, V., Fouling and cleaning of ultrafiltration membranes: A review, J. Water Process Eng. 1 (2014) 121. doi: https://doi.org/10.1016/j.jwpe.2014.04.003

23. Ng, C. J., Mohammad, A. W., Ng, L. Y., MdJahim, J., Membrane fouling mechanisms during ultrafiltration of skimmed coconut, J. Food Eng. 142 (2014) 190. doi: https://doi.org/10.1016/j.jfoodeng.2014.06.005

24. Guo, X., Gao, W., Li, J., Hu, W., Fouling and cleaning characteristics of ultrafiltration of hydrophobic dissolved organic matter by a polyvinyl chloride hollow fiber membrane, Water Environ. Res. 81(6) (2009) 626. doi: https://doi.org/10.2175/106143008X370368

25. Corbatón-Báguena, M. J., Alvarez-Blanco, S., Vincent-Vela, $M$. $C$., Fouling mechanisms of ultrafiltration membranes fouled with whey model solutions, Desalination 360 (2015) 87.

doi: https://doi.org/10.1016/j.desal.2015.01.019

26. Vincent-Vela, M. C., Blanco, S. Á., García, J. L., Rodríguez, $E$. B., Analysis of membrane pore blocking models adapted to crossflow ultrafiltration in the ultrafiltration of PEG, Chem. Eng. J. 149(1) (2009) 232. doi: https://doi.org/10.1016/j.cej.2008.10.027

27. Wibisono, Y., Nugroho, W. A., Chung, T.-W., Dry degumming of corn-oil for biodiesel using a tubular ceramic membrane, Proc. Chem. 9 (2014) 210. doi: https://doi.org/10.1016/j.proche.2014.05.025

28. Aryanti, N., Sandria, F. K. I., Putriadi, R. H., Wardhani, D. $H$., Evaluation of micellar-enhanced ultrafiltration (MEUF) membrane for dye removal of synthetic remazol dye wastewater, Eng. J. 21(3) (2017) 23.

doi: https://doi.org/10.4186/ej.2017.21.3.23

29. Aryanti, N., Wardhani, D. H., Supandi, S., Flux profiles and mathematical modeling of fouling mechanism for ultrafiltration of Konjac glucomannan, Chem. Chem. Eng. Biotech. Food Ind. 17(2) (2016) 125.

30. Aryanti, N., Sandria, F. K. I., Wardhani, D. H., Blocking mechanism of ultrafiltration and micellar-enhanced ultrafiltration membrane for removal from model waste water, Adv. Sci. Lett. 23 (2017) 2598. doi: https://doi.org/10.1166/asl.2017.8730

31. Hermia, J., Constant pressure blocking filtration laws-application to power-law non-Newtonian fluids, Trans. Ichem. E 160 (1982) 183.
32. Amin, I. N. H. M., Mohammad, A. W., Markom, M., Choe, P. L., Hilal, N., Analysis of deposition mechanism during ultrafiltration of glycerin-rich solutions, Desalination 261(3) (2010) 313.

doi: https://doi.org/10.1016/j.desal.2010.04.016

33. de Melo, J. R. M., Tres, M. V., Steffens, J., Oliveira, J. V., Di Luccio, M., Desolventizing organic solvent-soybean oil miscella using ultrafiltration ceramic membranes, J. Memb. Sci. 475 (2015) 357. doi: https://doi.org/10.1016/j.memsci.2014.10.029

34. Velu, S., Muruganandam L., Arthanareeswaran, G., Preparation and performance studies on polyethersulfone ultrafiltration membranes modified with gelatin for treatment of tannery and distillery wastewater, Brazilian J. Chem. Eng. 32(01) (2015) 179. doi: https://doi.org/10.1590/0104-6632.20150321s00002965

35. Vankelecom, I. F. J., De Smet, K., Gevers, L. E. M., Livingston, A., Nair, D., Aerts, S., Kuypers, S., Jacobs, P. A., Physico-chemical interpretation of the SRNF transport mechanism for solvent through dense silicone membranes, J. Memb. Sci. 231 (2004) 99. doi: https://doi.org/10.1016/j.memsci.2003.11.007

36. Machado, D. R., Hasson, D., Semiat, R., Effect of solvent properties on permeate flow through nanofiltration membranes. Part I: Investigation of parameters affecting solvent flux, J. Memb. Sci. 163 (1999) 93. doi: https://doi.org/10.1016/S0376-7388(99)00158-1

37. Araki, M., Coutinho, C., Goncales, L. A. G., Viotto, L. A., Solvent permeability in commercial ultrafiltration polymeric membranes and evaluation of the structural and chemical stability towards hexane, Sep. Purif. Technol. 71 (2010) 13. doi: https://doi.org/10.1016/j.seppur.2009.10.005

38. Penha, F. M., Rezzadori, K., Proner, M. C., Zin, G., Fogaça, L. A., Petrus, J. C. C., de Oliveira, J. V., Di Luccio, M., Evaluation of permeation of macauba oil and n-hexane mixtures through polymeric commercial membranes subjected to different pre-treatments, J. Food Eng. 155 (2015) 79. doi: https://doi.org/10.1016/j.jfoodeng.2015.01.020

39. Pagliero, C., Ochoa, N. A., Martino, P., Marchese, J., Separation of sunflower oil from hexane by use of composite polymeric membranes, J. Am. Oil Chem. Soc. 88 (2011) 1813. doi: https://doi.org/10.1007/s11746-011-1839-3

40. Manjula, S., Kobayashi, I., Subramanian, R., Characterization of phospholipid reverse micelles in nonaqueous systems in relation to their rejection during membrane processing, Food Res. Int. 44 (2011) 925. doi: https://doi.org/10.1016/j.foodres.2011.01.059

41. Kim, I.-C., Kim, J.-H., Lee, K.-H., Tak, T. M., Phospholipids separation (degumming) from crude vegetable oil by polyimide ultrafiltration membrane, J. Memb. Sci. 205 (2002) 113. doi: https://doi.org/10.1016/S0376-7388(02)00070-4

42. Pagliero, C., Mattea, M., Ochoa, N., Marchese, J., Fouling of polymeric membranes during degumming of crude sunflower and soybean oil, J. Food Eng. 78(1) (2007) 194. doi: https://doi.org/10.1016/j.jfoodeng.2005.09.015

43. Sehn, G. A. R., Gonçalves, L. A. G., Ming, C. C., Ultrafiltration-based degumming of crude ricebran oil using a polymer membrane, Grasas Y Aceites 7(1) (2016) 120. doi: https://doi.org/10.3989/gya.0498151

44. Pagliero, C., Ochoa, N., Marchese, J., Matte, M., Degumming of crude soybean oil by ultrafiltration using polymeric membranes, J. Am. Oil Chem. Soc. 78 (2001) 793. doi: https://doi.org/10.1007/s11746-001-0344-6 